\title{
Analgesic Usage for Low Back Pain: Impact on Health Care Costs and Service Use
}

\author{
Molly T. Vogt, PhD, ${ }^{*}$ C. Kent Kwoh, MD, ${ }^{*}$, Doris K. Cope, MD, ${ }^{*}$ Thaddeus A. Osial, MD, ${ }^{*}$ \\ Michael Culyba, MD, $\ddagger$ and Terence W. Starz, MD*
}

Study Design. Cross-sectional analysis of analgesic use by patients with low back pain (LBP).

Objectives. To describe patterns of analgesic use and their cost implications for the use of other care services among individuals with LBP enrolled in a health insurance plan during 2001. It was hypothesized that the use of analgesics would be most frequent among patients with LBP with neurologic findings.

Summary of Background Data. National guidelines have recommended analgesics as the primary pharmacologic treatment of LBP. The choice of specific analgesics has major cost and service use implications.

Methods. The University of Pittsburgh Health System includes 18 affiliated hospitals, more than 5000 physicians, and a commercial health plan with 255,958 members in 2001. This study uses the System Health Plan's insurance claims database to identify members who had services provided for one of 66 International Classification of Diseases, Version 9, Clinical Modification codes that identify mechanical LBP ( $n=17,148)$.

Results. In 2001, 7631 (43.5\%) members with claims for LBP services had no analgesic pharmacy claims. The other $9517(55.5 \%)$ had analgesics claims costing a total of $\$ 1.4$ million; $68 \%$ of claimants were prescribed an opioid and $58 \%$ nonselective nonsteroidal antiinflammatory drugs (NSAID). The costs of opioids, NSAID, and cyclooxygenase-2 selective NSAID for patients with LBP represented $48 \%, 24 \%$, and $28 \%$, respectively, of total health plan expenditures for all uses of these drugs, including cancer. Opioid use was associated with the high volume usage of LBP care services. Patients with LBP with and without neurologic involvement and those with acquired lumbar spine structural disorders had similar patterns of analgesic use: those with congenital structural disorders were less likely to use analgesics; and those with psychogenic pain and LBP related to orthopedic devices were more likely to use opioids.

Conclusions. With this health plan, a high proportion of patients with LBP had claims for opioids during 2001. The use of opioids by patients with LBP represents a major cost for the health plan, and is associated with specific patient characteristics and their use of other LBP services.

From the *University of Pittsburgh School of Medicine; +Pittsburgh Veterans Administration Healthcare System; and $\ddagger$ UPMC Health Plan, Pittsburgh, PA.

Acknowledgment date: July 28, 2003. First revision date: October 29, 2003. Second revision date: May 24, 2004. Third revision date: June 3, 2004. Acceptance date: June 4, 2004.

The manuscript submitted does not contain information about medical device(s)/drug(s).

No funds were received in support of this work. No benefits in any form have been or will be received from a commercial party related directly or indirectly to the subject of this manuscript.

Address correspondence and reprint requests to Molly T. Vogt, $\mathrm{PhD}$, Department of Orthopaedic Surgery, Suite 1010, 3471 Fifth Avenue, Pittsburgh, PA 15213; E-mail: vogtm@upmc.edu
Key words: analgesic usage, low back pain, insurance claims, opioids. Spine 2005;30:1075-1081

The total national expenditure for the care of low back pain (LBP) is estimated to range from $\$ 20$ to $\$ 50$ billion per year. ${ }^{1,2}$ Back pain is the second most common symptom reported by persons visiting their primary care physician $^{3}$ and the most frequent complaint of individuals seen by orthopedic surgeons, neurosurgeons, and occupational medicine physicians. ${ }^{4}$ It is the leading cause of physical disability among adults, and approximately $2 \%$ of the population is disabled because of spinal problems and related pain in any given year., ${ }^{2,5}$

LBP is classified by the anatomic structures affected along with the clinical symptomatology. ${ }^{6-8}$ The most common origin of LBP is from the musculoligamentous structures. However, discogenic abnormalities and apophyseal joint osteoarthritis can also be pain generators. Pain is usually localized to the low back and buttock areas but occasionally radiates to the lower leg with nerve root irritation or with lumbar canal stenosis. Serious underlying disorders such as infection, cancer, and fracture are uncommon causes of LBP.

Only $39 \%$ of affected individuals seek medical attention for LBP, ${ }^{9}$ and self-treatment with over-the-counter analgesics, rest, and heat are common. Typically, patients with acute LBP who see a physician receive educational information, including heat application and exercise recommendations, and advice on activity limitation. In addition, prescription analgesic drug therapy is often used to provide pain relief during the recovery process. Depending on the clinical findings and pain characteristics, magnetic resonance imaging (MRI) and computerized tomography (CT) studies, physical therapy, surgery, and other measures may be prescribed. ${ }^{6}$ Because the majority of individuals with acute LBP recover within 6 to 12 weeks, the relative value and use of the various interventions are areas of continued intensive investigation. ${ }^{10}$ As many as half of the patients will have recurrent episodes of LBP, and about $10 \%$ of patients have chronic symptoms. ${ }^{11-13}$

Guidelines for the treatment of LBP developed by the Agency for Health Care Policy and Research and other groups recommend that nonopioid analgesics, including acetaminophen and nonselective nonsteroidal antiinflammatory drugs (NSAID), be used first in the treatment of mild or moderate LBP. ${ }^{14}$ Selective cyclooxygenase- 2 (COX-2) inhibiting NSAID is appropriate for elderly in- 
dividuals and others at high risk for gastrointestinal bleeding. Centrally acting agents, such as nonnarcotic opioids (propoxyphene and tramadol) and narcotics, are also prescribed for moderate and severe back pain, but their usage for LBP remains controversial. ${ }^{15-19}$

The diagnostic and therapeutic treatment of LBP varies considerably related to physician training and specialty orientation. ${ }^{11,20}$ Because of the large number of patients with this symptomatology, variable duration of pain and functional impairment, and wide range of analgesic costs, the physician's choices of drug treatment have significant financial implications for health insurance plans.

The purpose of this study is to describe the pattern of analgesic medication use among individuals with LBP (due to mechanical causes) enrolled in a health insurance plan in southwestern Pennsylvania and to explore the implications of these patterns on the cost of care for these patients. Because the causes of LBP are multifactorial, the patients in this study are grouped into 4 main categories: (1) LBP without neurologic involvement, (2) LBP with neurologic involvement, (3) LBP caused by lumbar spine structural disorders (congenital or acquired), and (4) LBP due to other causes (including postoperative patients). It was hypothesized that the use of analgesics, particularly opioids, would be more frequent among the patients with neurologic findings.

\section{Methods}

The University of Pittsburgh Medical Center (UPMC) Health Plan is part of the UPMC Health System (UPMCHS). Covered entities include 18 affiliated hospitals and more than 5000 physicians. During 2001, 255,958 commercial members were enrolled in the health plan. The University of Pittsburgh Institutional Review Board approved the analysis of the data from the claims database.

Identification of Patients with LBP. Patients with low back problems were identified using an algorithm developed at the University of Washington in Seattle, which was based on 66 diagnosis codes from the International Classification of Diseases, Version 9, Clinical Modification (ICD-9-CM). ${ }^{21}$ This algorithm was designed to exclude patients with nonmechanical causes of LBP, such as malignancies, infection, and major trauma. The patients with LBP were then grouped into the following categories:

- Group I: back pain with no neurologic findings (ICD-

9-CM codes 724.2, 724.5, 846.0-846.9)

- Group II: back pain with neurologic findings (ICD-9-CM codes 721.42, 721.91, 722.73, 722.80, 724.3, 724.4)

- Group IIIa: congenital lumbar spine structural disorders (ICD-9-CM codes 737.1, 737.20, 737.3, 739.3, 739.4, $756.13-756.19)$

- Group IIIb: acquired lumbar spine structural disorders (ICD-9-CM codes 721.5-721.90, 722.10, 722.2, 722.30, $722.32,722.52,722.6,722.90,722.93,724.00,724.02$, $724.09,738.4,756.12)$

- Group IV: other (ICD-9-CM codes 307.89, 722.83, 724.6, 724.8, 724.9, 756.10, 805.4, 805.6, 805.8, 996.4).
Variables Available in the Claims Database. The UPMC Health Plan's insurance claims database contains information on the patient's age, sex, ICD-9-CM diagnosis code, variables for the National Drug Code, generic and specific brands of analgesics prescribed, number of pills, number of days supplied, office visits, physical therapy, chiropractic care, emergency room visits, hospital admissions, spinal injections (e.g., epidural and soft tissue injections), lumbar radiography, and MRI and CT studies. In addition, the actual expenditures by the health plan for these medications and LBP services were available. The following major categories of analgesics were identified: opioids, nonselective NSAID, and selective COX-2 inhibiting NSAID.

Data Analysis. Descriptive statistics, including measures of central tendency and dispersion, were computed for continuous data. Frequency distributions were determined for categorical variables. For continuous variables, the statistical significance of differences between groups was assessed using general linear modeling techniques. For categorical variables, the $\chi^{2}$ statistic was used to test for the statistical significance of differences between groups.

Logistic regression was used to calculate the odds ratios for factors associated with claims for any use and long-term (defined as more than 30 days) use of opioid medications. Two separate regression series were conducted using the following dichotomous dependent variables: any opioid use/no opioid use, and opioid use 30 days or less/opioid use more than 30 days. Univariate logistic regression was used to evaluate the association of the independent variables with each dependent variable. The independent variables, which were significantly associated with each dependent variable $(P<0.05)$, were then entered into a multivariate logistic regression model. Both backward and forward logistic regression were performed and yielded similar results. No significant interactions were found. Independent variables were used in the regressions as categorical variables, and dummy variables were constructed when necessary: age (18-40, 41-55, and $\geq 56$ years); sex (men, women); LBP groups (I, II, IIIa, IIIb, and IV); use of physical therapy services (yes/no); use of MRI/CT services (yes/no); use of chiropractic services (yes/no); lumbar radiograph (yes/no); one or more office visits during the year (yes/no); one or more emergency room visits during the year (yes/no); one or more hospital visits during the year (yes/no); and received a spinal injection (yes/no).

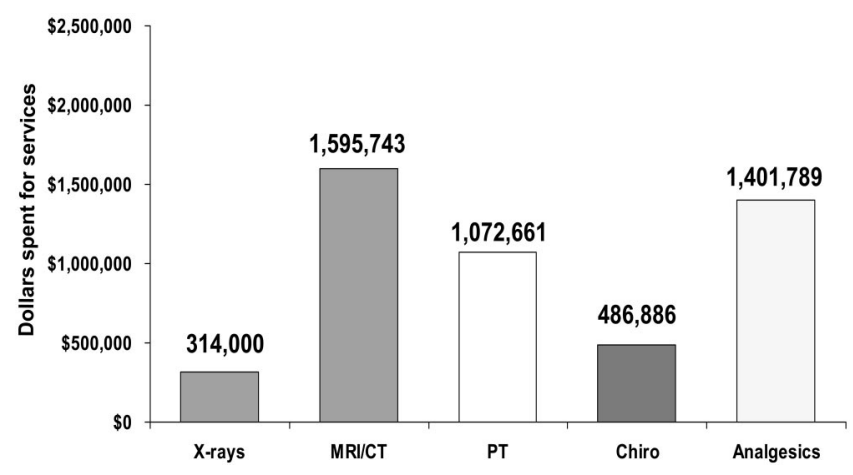

Figure 1. Cost of services for patients with LBP. Chiro, chiropractics; PT, physical therapy. 
Table 1. Characteristics and Service Usage of 17,148 Patients with LBP with Claims During 2001

No. of Patients $(\%)$

\begin{tabular}{lr}
\hline Age group (yrs) & \\
18-40 & $6386(37.2)$ \\
$41-55$ & $7369(43.0)$ \\
$\geq 56$ & $3393(19.8)$ \\
Men & $7477(43.6)$ \\
Groups & $13,074(76.2)$ \\
I & $1034(6.0)$ \\
II & $812(4.7)$ \\
IIIa & $1295(7.6)$ \\
IIIb & $933(5.4)$ \\
IV & $2477(14.4)$ \\
Physical therapy claim & $2752(16.1)$ \\
MRI/CT claim & $3191(18.6)$ \\
Chiropractic claim & $5296(30.9)$ \\
Lumbar x-ray claim & $1557(9.1)$ \\
Emergency room claim & $1747(10.2)$ \\
Spinal injection claim & $11,683(68.1)$ \\
Office visit claim & $415(2.4)$ \\
Hospital admission claim &
\end{tabular}

\section{Results}

Based on claims data for calendar year 2001, 17,148 health plan members $(6.7 \%$ of subscribers) had services provided for one of the 66 ICD-9-CM codes that identify LBP. Overall, $55 \%$ of patients with LBP had at least one claim for an analgesic medication at a cost to the health plan of $\$ 1,401,789,31 \%$ had lumbar radiographs costing $\$ 314,000,16 \%$ had MRI costing $\$ 1,475,713,3 \%$ had CT costing $\$ 120,030,19 \%$ received chiropractic care costing $\$ 486,886$, and $14 \%$ received physical therapy services costing $\$ 1,072,661$ (Figure 1).

LBP claimants were classified into the following groups: group I ( $\mathrm{n}=13,074)$, LBP with no neurologic findings; group II ( $\mathrm{n}=1034)$, LBP with neurologic findings; A groups IIIa ( $\mathrm{n}=812)$, LBP due to congenital structural abnormalities (e.g., scoliosis, spondylolisthesis) and group IIIb ( $\mathrm{n}=1295)$, LBP due to acquired structural abnormalities (e.g., lumbar canal stenosis); and group IV ( $\mathrm{n}=933)$, LBP related to other causes (postoperative diagnoses, psychogenic pain, or nonspecified pain) (Table 1). The average age of patients with LBP was 44.5 years; those in groups II and IIIb were $3-5$ years older than those in groups I and IIIa $(P>0.001)$. The majority of claimants $(56.5 \%)$ were women, and the gender distribution was similar across all groups except group IIIb (52.4\% women, $P<0.001)$.

Overall, 9517 patients with LBP $(55 \%$ of the those with any claim for LBP) had a claim for one or more prescription analgesic drugs. Of those patients with an analgesic claim, $68 \%(\mathrm{n}=6465)$ received an opioid, and $58 \%(\mathrm{n}=5538)$ received a COX-2 selective or nonselective NSAID. Thirty-three percent of the patients received an opioid alone, $27 \%$ a nonselective NSAID alone, $3 \%$ a COX-2 selective NSAID alone, $26 \%$ opioids and NSAID, and $9 \%$ opioids with a variety of other analgesic drugs.

\section{Analgesic use by LBP Group}

Claims for analgesic medications varied widely across the 5 groups (Table 2), ranging from a low of $33.5 \%$ with claims in group IIIa to a high of $63 \%$ with claims in group IV $(P<0.001)$. Considering specific categories of drugs, members with congenital structural conditions (group IIIa) had a lower frequency of claims for opioids $(P<0.001)$, nonselective NSAID $(P<0.001)$, and COX-2 selective NSAID $(P<0.001)$ than those in all other groups. The proportion of members in group IV with claims for opioids and for COX-2 selective NSAID were significantly higher $(P<0.001)$ than that in groups I and IIIa; claims for nonselective NSAID were lower in group IV than in group I $(P<0.001)$ (Table 2$)$.

Patients between 18 and 40 years of age were significantly $(P<0.001)$ less likely to have an analgesic claim than those 41 years and older. Similarly, they were less likely to have a claim for opioid or COX-2 selective NSAID (Table 2). The proportion of women with a pharmacy claim was higher than that of men $(57.4 \%$ vs. $53.1 \%$, respectively, $P<0.001)$. This sex difference was consistent across all groups for analgesic claims.

Table 2. Analgesic Claims by Patients with LBP During 2001

\begin{tabular}{|c|c|c|c|c|}
\hline & $\begin{array}{c}\% \text { of Any Analgesic } \\
\text { Pharmacy Claim }\end{array}$ & $\begin{array}{l}\% \text { of Opioid } \\
\text { Claims }\end{array}$ & $\begin{array}{c}\% \text { of Nonselective } \\
\text { NSAID Claims }\end{array}$ & $\begin{array}{c}\% \text { of COX-2 Selective } \\
\text { NSAID Claims }\end{array}$ \\
\hline $\begin{array}{l}\text { All patients with LBP } \\
\quad(\mathrm{n}=17,148)\end{array}$ & 55.5 & 37.7 & 32.3 & 5.8 \\
\hline \multicolumn{5}{|l|}{ Groups (n) } \\
\hline I $(13,074)$ & 56.7 & 38.2 & 33.8 & 5.4 \\
\hline II (1034) & 52.7 & 33.8 & 31.9 & 7.3 \\
\hline IIIa (812) & 33.5 & 21.7 & 17.5 & 3.7 \\
\hline IIIb (1295) & 54.2 & 36.6 & 30.0 & 8.2 \\
\hline IV (933) & 63.0 & 51.0 & 27.0 & 8.0 \\
\hline \multicolumn{5}{|l|}{ Gender (n) } \\
\hline Men (7477) & 53.1 & 36.5 & 30.6 & 4.5 \\
\hline Women (9671) & 57.4 & 38.6 & 33.6 & 6.8 \\
\hline \multicolumn{5}{|l|}{ Age categories (n) } \\
\hline $18-40$ Yrs (6386) & 51.5 & 34.6 & 32.3 & 1.8 \\
\hline $41-55$ Yrs (7369) & 57.5 & 39.5 & 31.3 & 6.3 \\
\hline$\geq 56$ Yrs (3393) & 58.6 & 39.6 & 33.4 & 12.1 \\
\hline
\end{tabular}




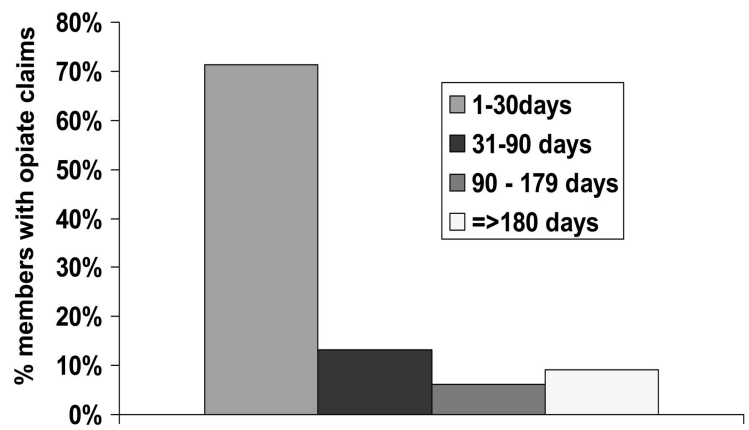

Figure 2. Duration of opioid use for claimants with LBP.

\section{Relationship Between Opioid Claims, Duration of Opioid Use, and Claims for Other Services}

The large majority of patients $(71.4 \%)$ who had pharmacy claims for opioids used these drugs for less than one month. However, $15.4 \%$ of the patients had opioid prescription claims for more than 90 days and $9.2 \%$ for more than 180 days (Figure 2).

Patients who had a claim for opioids were more likely to receive physical therapy services (odds ratio [OR] 1.5, 95\% confidence interval [CI] 1.4-1.6), use MRI or CT services (OR 2.6, 95\% CI 2.4-2.8), visit the emergency room (OR 3.3, 95\% CI 3.0-3.6), receive a spinal injection (OR 4.3, 95\% CI 3.9-4.8), or be admitted to the hospital (OR 12.4, 95\% CI 9.9-15.7) than those who did not have a claim for opioids (Table 3 ). The proportion of patients with claims for physical therapy and MRI varied among the 5 groups, but the odds ratios were similar in groups I-IIIb. The number of patients with claims for physical therapy and MRI in group IV was relatively small (Table 3 ). Patients who had an opioid claim were $58 \%$ less likely to visit a chiropractor than those with no opioid claims (OR 0.4, 95\% CI 0.4-0.5).

Based on multivariate analysis, the independent factors positively associated with opioid usage during 2001 were receiving physical therapy, having a spinal injection, using MRI or CT, using emergency room services, and being classified by ICD-9-CM code into group IV (Table 4). The increased use of radiographs and being female were also marginally associated with opioid use. Visiting a chiropractor was negatively associated with having an opioid claim $(\mathrm{OR}=0.5,95 \%$ CI $0.5-0.6)$. Patients 41-55 years of age and those with congenital structural problems in the lumbar spine (group IIIa) were less likely to use an opioid than other patients (Table 4).

Claimants who had extended opioid use (defined as 1 month or longer in duration) were more likely to be classified into group IV, to receive a spinal injection, have an office visit, and use the MRI or CT services than were the patients who had opioids prescribed for less than 1 month. In addition, less frequent use of emergency room and chiropractic services was associated with extended use of opioids. Women and patients 41-55 years old were also less likely to use opioids for an extended time (Table 4).
Table 3. Use of Nonanalgesic Services by Claimants With and Without Opioid Claims in 2001

\begin{tabular}{|c|c|c|c|}
\hline & $\begin{array}{c}\text { Opioid } \\
\text { Claim } \\
\text { (n }=6465)\end{array}$ & $\begin{array}{l}\text { No Opioid } \\
\text { Claim } \\
\text { (n }=10,683)\end{array}$ & $O R^{*}$ \\
\hline \multicolumn{4}{|l|}{ All claimants $(\mathrm{n}=17,148)$} \\
\hline Physical therapy (2477) & $17.7 \%$ & $12.5 \%$ & $1.5(1.4,1.6)$ \\
\hline MRI/CT (2752) & $24.2 \%$ & $11.1 \%$ & $2.6(2.4,2.8)$ \\
\hline Lumbar x-ray (5296) & $31.4 \%$ & $29.0 \%$ & $1.3(1.2,1.4)$ \\
\hline Chiropractic (3191) & $11.2 \%$ & $23.1 \%$ & $0.4(0.4,0.5)$ \\
\hline Spinal injection (1747) & $18.7 \%$ & $5.0 \%$ & $4.3(3.9,4.8)$ \\
\hline Office visit $(11,683)$ & $66.9 \%$ & $68.9 \%$ & $0.9(0.9,1.0)$ \\
\hline Emergency room (1557) & $15.4 \%$ & $5.3 \%$ & $3.3(3.0,3.6)$ \\
\hline Hospital admission (415) & $5.6 \%$ & $0.5 \%$ & $12.4(9.9,15.7)$ \\
\hline \multicolumn{4}{|l|}{$\begin{array}{l}\text { Group I claimants } \\
\qquad(\mathrm{n}=13,074)\end{array}$} \\
\hline Physical therapy (2060) & $19.5 \%$ & $13.5 \%$ & $1.6(1.4,1.7)$ \\
\hline MRI/CT (2264) & $26.6 \%$ & $11.6 \%$ & $2.8(2.5,3.0)$ \\
\hline Lumbar x-ray (4287) & $37.3 \%$ & $30.0 \%$ & $1.4(1.3,1.5)$ \\
\hline Chiropractic (2131) & $10.3 \%$ & $20.0 \%$ & $0.5(0.4,0.5)$ \\
\hline Spinal injection (1481) & $20.8 \%$ & $5.5 \%$ & $4.5(4.1,5.1)$ \\
\hline Office visit (9404) & $72.5 \%$ & $71.6 \%$ & $1.1(1.0,1.1)$ \\
\hline Emergency room (1484) & $19.0 \%$ & $6.6 \%$ & $3.3(3.0,3.7)$ \\
\hline Hospital admission (338) & $6.0 \%$ & $0.5 \%$ & $13.5(10.4,17.6)$ \\
\hline \multicolumn{4}{|l|}{$\begin{array}{l}\text { Group II claimants } \\
\qquad(\mathrm{n}=1034)\end{array}$} \\
\hline Physical therapy (159) & $18.5 \%$ & $13.7 \%$ & $1.4(1.0,2.0)$ \\
\hline MRI/CT (178) & $24.2 \%$ & $13.5 \%$ & $2.0(1.5,2.8)$ \\
\hline Lumbar x-ray (235) & $20.8 \%$ & $23.7 \%$ & $0.8(0.6,1.2)$ \\
\hline Chiropractic (230) & $11.5 \%$ & $27.7 \%$ & $0.4(0.2,0.5)$ \\
\hline Spinal injection (84) & $12.8 \%$ & $5.7 \%$ & $2.4(1.6,3.8)$ \\
\hline Office visit (760) & $75.3 \%$ & $72.5 \%$ & $1.2(0.9,1.6)$ \\
\hline Emergency room (33) & $6.3 \%$ & $1.6 \%$ & $4.1(2.1,8.1)$ \\
\hline Hospital admission (20) & $5.1 \%$ & $0.4 \%$ & $12.3(4.7,32.5)$ \\
\hline \multicolumn{4}{|l|}{$\begin{array}{l}\text { Group IIla claimants } \\
\qquad(\mathrm{n}=812)\end{array}$} \\
\hline Physical therapy (57) & $9.7 \%$ & $6.3 \%$ & $1.6(0.9,12.8)$ \\
\hline MRI/CT (21) & $6.3 \%$ & $1.6 \%$ & $4.2(1.9,9.4)$ \\
\hline Lumbar x-ray (241) & $30.7 \%$ & $29.4 \%$ & $1.1(0.7,1.5)$ \\
\hline Chiropractic (447) & $55.7 \%$ & $54.9 \%$ & $(0.7,1.5)$ \\
\hline Spinal injection (8) & $2.8 \%$ & $0.5 \%$ & $6.2(1.7,21.9)$ \\
\hline Office visit (507) & $57.8 \%$ & $63.7 \%$ & $0.8(0.6,1.1)$ \\
\hline Emergency room (1) & $0.6 \%$ & - & - \\
\hline Hospital admission (0) & - & - & - \\
\hline \multicolumn{4}{|l|}{$\begin{array}{l}\text { Group IIIb claimants } \\
\qquad(\mathrm{n}=1295)\end{array}$} \\
\hline Physical therapy (138) & $12.7 \%$ & $9.5 \%$ & $1.4(1.0,2.0)$ \\
\hline $\mathrm{MRI} / \mathrm{CT}(262)$ & $26.4 \%$ & $16.7 \%$ & $1.8(1.4,2.4)$ \\
\hline Lumbar x-ray (381) & $31.2 \%$ & $28.4 \%$ & $1.2(0.9,1.5)$ \\
\hline Chiropractic (181) & $6.5 \%$ & $18.3 \%$ & $0.3(0.2,0.5)$ \\
\hline Spinal injection (117) & $17.3 \%$ & $4.3 \%$ & $4.7(3.2,6.9)$ \\
\hline Office visit (740) & $54.4 \%$ & $58.7 \%$ & $0.8(0.7,1.1)$ \\
\hline Emergency room (9) & $1.7 \%$ & $0.1 \%$ & $14.1(2.9,68.8)$ \\
\hline Hospital admission (33) & $5.9 \%$ & $0.6 \%$ & $10.3(4.7,22.4)$ \\
\hline \multicolumn{4}{|l|}{ Group IV claimants $(\mathrm{n}=933)$} \\
\hline Physical therapy (63) & $5.9 \%$ & $7.7 \%$ & $0.8(0.5,1.3)$ \\
\hline MRI/CT (27) & $3.4 \%$ & $2.4 \%$ & $1.4(0.7,3.1)$ \\
\hline Lumbar x-ray (152) & $14.4 \%$ & $18.2 \%$ & $0.8(0.5,1.1)$ \\
\hline Chiropractic (202) & $8.9 \%$ & $35.0 \%$ & $0.2(0.1,0.3)$ \\
\hline Spinal injection (57) & $8.2 \%$ & $4.0 \%$ & $2.2(1.2,3.8)$ \\
\hline Office visit (272) & $17.3 \%$ & $41.5 \%$ & $0.3(0.2,0.4)$ \\
\hline Emergency room (30) & $3.6 \%$ & $2.9 \%$ & $1.3(0.6,2.6)$ \\
\hline Hospital admission (24) & $3.8 \%$ & $1.1 \%$ & $3.6(1.3,9.1)$ \\
\hline
\end{tabular}

${ }^{*}$ Members with no opioid claim used as the referent group. $\mathrm{OR}=$ odds ratio

\section{Health Plan Costs for Analgesics}

Total pharmacy costs for analgesics in 2001 were $\$ 1,401,789$ or $\$ 147.30$ per patient with LBP with an analgesic claim. Among the ICD-9-CM groups, there was considerable variation in average costs, ranging 
Table 4. Odds Ratios From a Multiple Logistic Regression Analysis of Correlates for Opioid Use Among Patients with LBP

\begin{tabular}{|c|c|c|}
\hline & $\begin{array}{c}\text { OR }(95 \% \mathrm{Cl}) \text { for } \\
\text { Any Opioid Use } \\
\text { (n }=17,148)\end{array}$ & $\begin{array}{l}\text { OR }(95 \% \mathrm{Cl}) \text { for } \\
\text { Opioid Use } \geq 1 \mathrm{mo} \\
(\mathrm{n}=6465)^{*}\end{array}$ \\
\hline \multicolumn{3}{|l|}{ Age (yrs) } \\
\hline $18-40$ & 1.0 & 1.0 \\
\hline $41-55$ & $0.8(0.8,0.9)$ & $0.6(0.5,0.7)$ \\
\hline$\geq 56$ & $1.0(0.9,1.1)$ & $1.0(0.9,1.2)$ \\
\hline Females & $1.1(1.0,1.2)$ & $0.9(0.8,1.0)$ \\
\hline \multicolumn{3}{|l|}{ Groups } \\
\hline 1 & 1.0 & 1.0 \\
\hline II & $0.9(0.8,1.1)$ & $0.8(0.7,1.1)$ \\
\hline IIla & $0.8(0.7,0.9)$ & $0.9(0.6,1.1)$ \\
\hline IIllb & $1.0(0.9,1.1)$ & $1.1(0.9,1.3)$ \\
\hline IV & $2.3(2.0,2.7)$ & $1.5(1.2,1.9)$ \\
\hline $\begin{array}{l}\text { Use of physical therapy } \\
\text { services }\end{array}$ & $1.2(1.1,1.3)$ & - \\
\hline Use of MRI/CT services & $1.9(1.7,2.0)$ & $1.5(1.3,1.7)$ \\
\hline Use of chiropractic services & $0.5(0.5,0.6)$ & $0.5(0.4,0.6)$ \\
\hline Lumbar x-ray & $1.1(1.0,1.2)$ & $0.9(0.8,1.0)$ \\
\hline$\geq 1$ Office visits during year & - & $1.3(1.1,1.5)$ \\
\hline $\begin{array}{l}\geq 1 \text { Emergency room visits } \\
\text { during year }\end{array}$ & $2.5(2.2,2.9)$ & $0.6(0.5,0.8)$ \\
\hline Spinal injection & $2.7(2.4,3.0)$ & $2.5(2.1,2.9)$ \\
\hline
\end{tabular}

*Only patients with LBP who received opioids were included in this regression; referent group is patients who received opiods for less than 1 month.

from a high of $\$ 230.32$ for patients in group IV to a low of $\$ 85.10$ for patients in group IIIa. Total annual analgesic costs per claimant were $21 \%$ higher for men $(\$ 163.62)$ than women $(\$ 135.50)$, partly because of opioids costs being $52 \%$ more in men compared to women (Table 5).

Annual health plan analgesic costs for younger claimants were less than half of those for claimants 41 years and older. In addition, costs per claimant were lower in each category of analgesic for these younger patients. Opioid costs were highest per claimant among those patients 41-55 years old, while nonselective NSAID and COX-2 costs were highest among those 56 years and older.

In 2001, the total cost of opioids in the health plan for all diagnoses was $\$ 1,795,375$. The cost of opioids for patients with LBP constituted almost half $(48 \%)$ of that amount. Opioid claims for patients with ICD-9-CM codes for cancer $(n=13,054)$ cost the health plan $\$ 377,029$ or $21 \%$ of the total yearly opioid costs. The costs of nonselective NSAID and COX-2 selective NSAID for LBP represented $24 \%$ and $28 \%$, respectively, of the total health plan expenditures for all uses of these drugs.

\section{Discussion}

During 2001, only approximately half of the members of the health plan with LBP made a claim for an analgesic drug. The cost of analgesic drugs used by these patients was comparable to the amount of money expended on MRI and CT studies, and physical therapy services for the treatment of back pain. Thirty-eight percent of patients with LBP had claims for opioids, and $9 \%$ received more than a 30-day supply of opioids. Overall, the cost to the health plan for opioid claims by patients with LBP represented nearly half of all opioid costs for all diagnoses, while claims by patients with cancer accounted for $21 \%$ of opioid costs.

National guidelines have recommended acetaminophen and nonselective NSAID analgesics as the primary pharmacologic treatment for LBP. ${ }^{14}$ However, the shortterm use of opioids is considered to be an option. During the last few years, several studies have attempted to determine the extent to which community physicians follow these guidelines. In 1998, Di Iorio et al ${ }^{22}$ surveyed primary care physicians in Northern Illinois using a questionnaire based on the Agency for Health Care Policy and Research acute LBP guidelines. Of the 182 physicians, 87 completed the survey, and the investigators concluded that many clinicians did not follow the treatment guidelines for back pain. For example, more than half $(62 \%)$ of the physicians reported prescribing opioids for LBP symptoms. Other primary care patient studies have found that $10 \%$ to $15 \%$ of patients with LBP receive opioids, and about $60 \%$ receive nonselective NSAID. ${ }^{3,23-25}$ On the other hand, relatively few $(3.4 \%)$

Table 5. Total Costs and Per Claimant Costs* Associated with LBP Pharmacy Claims for Analgesics During 2001

\begin{tabular}{|c|c|c|c|c|}
\hline & $\begin{array}{c}\text { All Pharmacy \$ } \\
\text { Costs }\end{array}$ & $\begin{array}{l}\text { Opioid } \\
\$ \text { Costs }\end{array}$ & $\begin{array}{l}\text { Nonselective } \\
\text { NSAID \$ Costs }\end{array}$ & $\begin{array}{l}\text { COX-2 Selective } \\
\text { NSAID \$ Costs }\end{array}$ \\
\hline $\begin{array}{l}\text { All patients with LBP } \\
(\mathrm{n}=17,148)\end{array}$ & $1,401,789(147.30)$ & $861,779(133.29)$ & 184,594 (133.33) & $324,256(326.01)$ \\
\hline \multicolumn{5}{|l|}{ Groups (n) } \\
\hline I $(13,074)$ & $1,044,835(140.95)$ & $660,081(132.17)$ & $137,937(31.21)$ & $223,747(316.93)$ \\
\hline II (1034) & $68,176(125.09)$ & $28,852(82.67)$ & $11,572(35.07)$ & 25,709 (339.28) \\
\hline IIIa (812) & $23,149(85.10)$ & 5397 (30.63) & 6637 (46.71) & $10,373(345.26)$ \\
\hline IIIb (1295) & $130,203(185.50)$ & $68,290(144.08)$ & 18,934 (48.74) & $38,868(366.02)$ \\
\hline IV (933) & $135,429(230.32)$ & $99,160(208.32)$ & 9514 (37.75) & $25,559(343.90)$ \\
\hline \multicolumn{5}{|l|}{ Gender (n) } \\
\hline Men (7477) & 649,618 (163.62) & $453,642(166.22)$ & 69,798 (30.51) & 115,839 (344.28) \\
\hline Women (9671) & $752,172(135.50)$ & 408,137 (109.33) & $114,796(35.33)$ & 208,418 (316.92) \\
\hline \multicolumn{5}{|l|}{ Age categories (n) } \\
\hline $18-40$ Yrs (6386) & $261,084(79.39)$ & 198,383 (89.78) & $31,660(15.35)$ & $22,775(198.13)$ \\
\hline 41-55 Yrs (7369) & $763,996(180.30)$ & $511,716(175.80)$ & $85,397(37.02)$ & 149,937 (322.97) \\
\hline$\geq 56$ Yrs (3393) & $376,710(189.46)$ & $151,680(112.89)$ & $67,537(59.60)$ & 151,544 (369.12) \\
\hline
\end{tabular}


spine patients treated at specialty spine centers in the United States were given opioids. ${ }^{26}$

To our knowledge, the current study is the first to examine the patterns of the use of analgesics among a large cohort of patients with LBP. During 2001, more than one third of the health plan members with LBP claims received opioids, with $9 \%$ using them for more than one month. LBP is the common diagnosis for which opioids are prescribed in the health plan.

Recent reviews have concluded that there is little evidence of the long-term efficacy of opioid analgesics for the treatment of refractory back pain. However, the use of opioids for the treatment of chronic and severe pain is growing. ${ }^{17,27,28}$ Empirical evidence suggests that these drugs help a limited number of patients, but some studies do show substantial gains in function and return to work rates with opioid use. ${ }^{6,8,19,29}$ The American Society of Pain and other professional groups ${ }^{30}$ recommend close monitoring (monthly visits) of patients who are on prolonged regimens of narcotics. Our data show only a minor increase in the number of office visits among the long-term users of opioids (Table 4).

Research done in the 1970s suggested that women were more likely to have an opioid prescribed for pain than men. ${ }^{31}$ The current study supports this finding but also showed that women were somewhat less likely to have opioid claims for more than a month's supply of pills. A recent study by Turk and Okifuji ${ }^{32}$ found that in a group of 191 patients referred to a multidisciplinary pain center, the likelihood of a patient with chronic pain receiving an opioid prescription was similar in both men and women. This inconsistency with our study may be related to differences in the patient characteristics. In addition, their cohort was a relatively small but heterogeneous group of patients with chronic pain (only $22 \%$ had LBP), while our large cohort included all patients in the health plan with a claim for LBP (both patients with acute and chronic). It is also noteworthy that in our study, the cost of the opioids prescribed for men was $52 \%$ higher than those prescribed for women.

Several studies have shown that a large proportion of health care expenditures can be attributed to a minority of patients across a wide variety of diagnoses. ${ }^{33-35}$ Engel et $a l^{36}$ found that this general observation also holds true for patients with back pain who are in the primary care setting. For example, one fifth of the patients with LBP enrolled in the Group Health Cooperative of Puget Sound accounted for more than half of the analgesic claims, $51 \%$ of the radiology claims, $91 \%$ of the LBP specialty visits, and $55 \%$ of the primary care follow-up visits for back pain. ${ }^{36}$ Overall, these patients accounted for approximately two thirds of the total expenditures for LBP in that health maintenance organization. The results from the current study are consistent with those reported by the Group Health Cooperative. Specifically, our data revealed that one group of patients with LBP (the 38\% who had claims for opioids) were higher users of other LBP care services.
Patients with LBP who used opioids were only about half as likely to receive treatment from a chiropractor as were nonusers. Although chiropractic and physical therapy services have been equally effective in reducing back pain symptoms, ${ }^{37,38}$ the use of physical therapy was increased by approximately $50 \%$ among opioid users in our study. To our knowledge, decreased chiropractic care by LBP opioid users has not been reported previously. Because opioid use for the treatment of LBP has been influenced by both patient attitudes to pain and physician practice style, ${ }^{20,31,32,39}$ we speculate that referral to a chiropractor might be negatively influenced by the same factors.

The majority of patients $(76 \%)$ were assigned an ICD9-CM code that placed them in group I (i.e., "LBP with no neurologic involvement."). This proportion is consistent with previous reports that the majority of patients visiting physicians have acute mechanical back pain of musculoligamentous origin. ${ }^{6}$ However, it is surprising that our results showed that patients in groups I and II (without and with neurologic findings, respectively,) had similar use of analgesics and other LBP services. We expected that patients with neurologic findings would be those with recurrent and/or chronic pain and, therefore, more likely to be receiving opioids and other analgesic medications. Patients in group IV had diverse diagnoses, but almost half were being treated for complications related to internal orthopedic devices, and another one third had unspecified back pain. More than half the patients in this group had claims for opioids, a significantly higher percentage than in the other groups. In addition, they were more likely to use opioids for more than 1 month. Conversely, these patients were less likely to have had radiographs or imaging studies during the year or to have received physical therapy. This result suggests that patients in group IV have more chronic and persistent symptoms than patients with LBP in other groups.

Our study has several limitations. The results are dependent on the accuracy of the ICD-9-CM coding by health care providers, and independent verification of the LBP diagnosis was not available in the insurance database. Further studies are needed to examine the impact of misclassification errors in this type of database. Also, there was no measure of the severity or duration of the LBP that could be determined from the insurance claim information. Because the members of the health plan are currently working or are family of the worker, there may be a "healthy worker" bias, resulting in an underestimation of the true prevalence of LBP and of analgesic use. However, this possibility is unlikely because the prevalence of opioid use is higher than reported in other studies. A further limitation of the study is that, although patients with a cancer diagnosis were excluded, the effects of other comorbid conditions on the use of analgesics were not considered. However, all pharmacy claims included in this dataset were linked specifically in response to a patient-clinician interaction, with an ICD-9 diagnostic code for LBP. In addition, although our study includes data for a calendar year, it is essentially cross- 
sectional in nature. Thus, the results cannot fully address the variations in claim patterns across the complete longitudinal course of all patients with LBP. A major strength of the study is the large sample size and the use of validated methodology using ICD-9-CM codes to identify patients with LBP in a claims database.

\section{- Conclusions}

This study shows the use of an administrative insurance database from a large health plan to describe the patterns of analgesic use in patients with LBP during the calendar year 2001. It is apparent that the prevalence of opioid use for treating these patients in southwestern Pennsylvania is much higher than previously reported. The opioid users also receive a high volume of other LBP care services. The available data do not allow us to determine whether the use of opioids by almost $40 \%$ of these patients with LBP is appropriate. Further research is needed. However, the results suggest that it may be useful to establish physician education programs based on national guidelines for the care of patients with LBP and to examine further analgesic prescribing patterns as they relate to other care activities for LBP.

\section{- Key Points}

- More than half of patients $(55.5 \%)$ with a primary diagnosis of mechanical LBP had an insurance claim for analgesics during 2001; 38\% received an opioid, $32 \%$ a nonselective nonsteroidal antiinflammatory drug, and $6 \%$ a selective COX-2 inhibiting NSAID.

- Analgesic use was similar among patients with LBP, with and without neurologic involvement.

- Of the patients with an opioid claim, $29 \%$ received more than a 30 -day supply, and $9 \%$ received more than a 180-day supply of the medication.

- Opioid use was associated with the high volume usage of other LBP care services.

- Total analgesic costs per claimant were higher for men than women; costs for opioids were $52 \%$ higher in men.

\section{References}

1. Frymoyer JW, Durett CL. The economics of spinal disorders. In: Frymoyer JW, Ducker TB, Hadler NM, et al, eds. The Adult Spine: Principles and Practice. Philadelphia, PA: Lippincott-Raven; 1997:143-50.

2. Smith MD, McGhan WF. Treating back pain without breaking the bank. Bus Health 1998;16:50-1.

3. Hart LG, Deyo RA, Cherkin DC. Physician office visits for low back pain. Frequency, clinical evaluation, and treatment patterns from a U.S. national survey. Spine 1995;20:11-9.

4. Cypress BK. Characteristics of physician visits for back symptoms: A national perspective. Am J Public Health 1983;73:389-95.

5. Kelsey JL, White AA. Epidemiology and impact of low back pain. Spine 1980;5:133-142.

6. Deyo RA, Weinstein JN. Low back pain. N Engl J Med 2001;344:363-70.

7. von Korff M, Saunders K. The course of back pain in primary care. Spine 1996;21:2833-7.

8. Atlas SJ, Deyo RA. Evaluating and managing acute low back pain in the primary care setting. J Gen Int Med 2001;16:120-31.
9. Carey TS, Evans AT, Hadler NM, et al. Acute severe low back pain. A population-based study of prevalence and care-seeking. Spine 1996;21:339-44.

10. van Tulder MW, Koes BW, Bouter LM. Conservative treatment of acute and chronic nonspecific low back pain: A systematic review of randomized controlled trials of the most common interventions. Spine 1997;22:2128-56.

11. Carey TS, Garrett J, Jackman A, et al. The outcomes and costs of care for acute low back pain among patients seen by primary care practitioners, chiropractors, and orthopedic surgeons. N Engl J Med 1995;333:913-7.

12. von Korff M, Deyo RA, Cherkin D, et al. Back pain in primary care. Outcomes at 1 year. Spine 1993;18:855-62.

13. Croft PRM, Macfarlane GJ, Papageorgiou AC, et al. Outcome of low back pain in general practice: A prospective study. BMJ 1998;316:1356-9.

14. Clinical Practice Guideline Number 14: Acute Low Back Problems in Adults. Rockville, MD: Agency for Health Care Policy and Research, US Dept of Health and Human Services; 1994. AHCPR publication 95-0643.

15. Deyo R. Drug therapy for back pain: Which drugs help which patients? Spine 1996;21:2840-9.

16. Murphy TM. Chronic opioids for chronic low back pain-Solution or problem? J Am Board Fam Pract 1996;9:225-8.

17. Brown RL, Fleming MF, Patterson JJ. Chronic opioid analgesic therapy for chronic low back pain. J Am Board Fam Pract 1996;9:191-204.

18. Ellis J. Opioid therapy and chronic low back pain. J Am Board Fam Pract 1996;9:386-7.

19. Bartleson JD. Evidence for and against the use of opioid analgesics for chronic nonmalignant pain. Pain Med 2002;3:260-71.

20. Bartfield JM, Salluzzo RF, Raccio-Robak N, et al. Physician and patient factors influencing the treatment of low back pain. Pain 1997;73:209-11.

21. Cherkin DC, Deyo RA, Volinn E, et al. Use of the international classification of diseases (ICD-9-CM) to identify hospitalizations for mechanical low back problems in administrative databases. Spine 1992;17:817-24.

22. Di Iorio D, Henley E, Doughty A. A survey of primary care physician practice pattern and adherence to acute low back problem guidelines. Arch Fam Med 2000;9:1015-21.

23. Cherkin DC, Wheeler KJ, Barlow W, et al. Medication use for low back pain in primary care. Spine 1998;23:605-14.

24. Frazier LM, Carey TS, Lyles MF, et al. Lengthy bed rest prescribed for low back pain: Experience at three general medicine walk-in clinics. South Med 1991;84:603-6.

25. Branthaver B, Stein GF, Mehran A. Impact of a medical back care program on utilization of services and primary care physician satisfaction in a large, multispecialty group practice health maintenance organization. Spine 1995; 20:1165-9.

26. Fanciullo GJ, Ball PA, Girault G, et al. An observational study on the prevalence and pattern of opioid use in 25,479 patients with spine and radicular pain. Spine 2002;27:201-5.

27. Portenoy RK. Opioid therapy for chronic nonmalignant pain: A review of the critical issues. J Pain Symptom Manage 1996;11:203-17.

28. Weber RJ. Opioids: Underused and abused drugs. Pain Forum 1996;5:240-3.

29. Schofferman J. Long-term opioid analgesic therapy for severe refractory lumbar spine plan. Clin J Pain 1999;15:136-40.

30. Federation of State Medical Boards of the US. Model Guidelines for the Use of Controlled substances for the Treatment of Pain. Euless, TX: Federation of State Medical Boards of the US, Inc.; 1998.

31. Jensen I, Nygren $\AA$, Gamberale F, et al. Coping with long-term musculoskeletal pain and its consequences: Is gender a factor? Pain 1994;57:167-72.

32. Turk D, Okifuji A. What factors affect physicians' decisions to prescribe opioids for chronic non-cancer pain patients? Clin J Pain 1997;13:330-6.

33. Freeborn DK, Pope CR, Mullooly JP, et al. Consistently high users of medical care among the elderly. Med Care 1990;28:527-540.

34. McFarland BH, Freeborn DK, Mullooly JP, et al. Utilization patterns among long-tern enrollees in a pre-paid group practice health maintenance organization. Med Care 1985;23:1221-33.

35. Alexandre LM. High-cost patients in a fee-for-service medical plan; the case for earlier intervention. Med Care 1990;28:112-23.

36. Engel CC, Von Korff M, Katon WJ. Back pain in primary care: Predictors of high health-care costs. Pain 1996;65:197-204.

37. Skargen EI, Oberg BE, Carlsson PG, et al. Cost and effectiveness analysis of chiropractic and physiotherapy treatment for low back and neck pain. Spine 1997;22:2167-77.

38. Hurwitz EL, Morgenstern H, Harber P, et al. A randomized trial of medical care with and without physical therapy and chiropractic care with and without physical modalities for patients with low back pain: 6-month follow-up outcomes from the UCLA Low Back Pain study. Spine 2002;27:2193-204.

39. Greer S, Dickerson VM, Schneiderman LJ, et al. Responses of male and female physicians to medical complaints in male and female patients. J Fam Pract 1986;21:49-53. 